\title{
Learning and Networking: Utilization of a Primary Care Listserv by Pharmacists
}

\author{
Melanie Trinacty, Barbara Farrell, Theresa J Schindel, Lisa Sunstrum, Lisa Dolovich, Natalie Kennie, \\ Grant Russell, and Nancy Waite
}

\begin{abstract}
Background: Expanding into new types of practice, such as family health teams, presents challenges for practising pharmacists. The Primary Care Pharmacy Specialty Network (PC-PSN) was established in 2007 to support collaboration among pharmacists working in primary care. The PC-PSN offers to its members a listserv (also referred to as an electronic mailing list) jointly hosted by the Canadian Society of Hospital Pharmacists and the Canadian Pharmacists Association.
\end{abstract}

Objectives: To characterize PC-PSN membership and participation in the listserv and to examine how the listserv is used by analyzing questions posted, concerns raised, and issues discussed.

Methods: Qualitative content analysis was used to examine 1 year of archived PC-PSN listserv posts from the year 2010. Two coders used NVivo software to classify the content of posts. Research team members reviewed and discussed the coding reports to confirm themes emerging from the data.

Results: Overall, 129 people $(52.9 \%$ of the 244 listserv members registered at the end of the calendar year) posted to the listserv during the study period. These participants worked in various practice settings, with over half residing in Ontario (68/129 [52.7\%]). A total of 623 posts were coded. Agreement between coders, for a sample of posts from 10 users, was acceptable (kappa $=0.78)$. The listserv was used to share information on a diverse set of topics, to support decision-making and acquire solutions for complex problems, and as a forum for mentorship.

Conclusions: The qualitative content analysis of the PC-PSN listserv posts for the year 2010 showed that the listserv was a medium for informationsharing and for providing and receiving support, through mentorship from colleagues. Apparent learning needs included effective question-posing skills and application of evidence to individual patients.

Keywords: pharmacy, listserv, social media, social networking, primary care

Can J Hosp Pharm 2014;67(5):343-52

\section{RÉSUMÉ}

Contexte : Passer à de nouveaux types de pratiques, comme les groupes de médecine de famille, présente différents défis pour les pharmaciens en exercice. Le Réseau de spécialistes en pharmacie (RSP) en soins de santé primaires a été mis sur pied en 2007 dans le but de favoriser la collaboration entre pharmaciens œuvrant en soins de santé primaires. Le RSP en soins de santé primaires offre à ses membres un gestionnaire de liste de diffusion (listserv) sous l'égide conjoint de la Société canadienne des pharmaciens d'hôpitaux et de l'Association des pharmaciens du Canada.

Objectifs : Offrir un portrait des effectifs du RSP en soins de santé primaires et de la participation des membres au forum de discussion, et étudier comment le gestionnaire de liste de diffusion est utilisé à l'aide d'une analyse des questions publiées, des préoccupations soulevées et des problèmes abordés.

Méthodes : Une analyse qualitative du contenu a servi à étudier l'ensemble des messages archivés dans le gestionnaire de liste de diffusion de l'année 2010. Deux codeurs ont utilisé le logiciel NVivo pour classer le contenu des messages publiés. Les résultats de l'encodage ont été examinés par les membres de l'équipe de recherche afin d'identifier les thèmes se dégageant des données.

Résultats : Dans l'ensemble, 129 personnes (52,9\% des 244 membres inscrits au gestionnaire de liste de diffusion à la fin de l'année civile) ont publié des messages durant la période à l'étude. Les participants travaillaient dans différents milieux et plus de la moitié habitaient en Ontario (68/129 [52,7\%]). Au total, 623 messages ont été encodés et la concordance entre les résultats des deux codeurs était satisfaisante pour un échantillon de messages provenant de 10 usagers (indice kappa $=0,78$ ). Le gestionnaire de liste de diffusion a servi à partager de l'information sur une gamme de sujets, à appuyer des prises de décision et à trouver des solutions à des problèmes complexes. Il a aussi servi de forum de mentorat.

Conclusions : L'analyse qualitative du contenu des messages publiés en 2010 dans le gestionnaire de liste de diffusion par les membres du RSP en soins de santé primaires a montré que le gestionnaire est un média d'échange d'information et qu'il permet d'offrir et de recevoir du soutien grâce au mentorat entre collègues. Parmi les besoins identifiés, on compte la capacité à bien formuler des questions et l'application des données probantes pour le traitement individuel des patients.

Mots clés : pharmacie, gestionnaire de liste de diffusion, médias sociaux, réseautage social, soins de santé primaires

[Traduction par l'éditeur] 


\section{INTRODUCTION}

$\mathrm{P}$ harmacists worldwide are embracing new roles, adapting to new regulations, and contributing to patient care in new practice settings. ${ }^{1}$ In Canada, many pharmacists work collaboratively with other health care professionals, including nurses and physicians in family practice, clinic teams, and other practice settings, and some community pharmacists are remunerated for patient care services. ${ }^{2}$ Over 100 pharmacists have joined Family Health Teams in Ontario, and about 25 pharmacists in Saskatchewan and 35 in Alberta are working in family practices. Other provinces report increasing numbers of pharmacists collaborating with family physicians (D. Jorgenson, executive member, Canadian Society of Hospital Pharmacists [CSHP]/ Canadian Pharmacists Association [CPhA] Primary Care Pharmacy Specialty Network, personal communication, August 1, 2013). Evolving professional roles and responsibilities in primary care present challenges and opportunities for pharmacists and necessitate collaboration with other health care professionals, as well as with colleagues within the profession. ${ }^{3}$

Strategies for collaborative learning, networking, and sharing information among pharmacists have included communication by e-mail listservs for at least 2 decades. ${ }^{4-6}$ Although listservs are increasingly used to share knowledge in many professional networks, little has been published about how pharmacists use them..$^{7-11}$

Listserv communication has been used in different ways within the health care system, including caregiver support, peer support for individuals with various diseases, and as an information-sharing tool for health care professionals. ${ }^{8-10,12,13}$ The latter have used listservs for networking, for sharing resources, and for accessing the expert opinions of colleagues. ${ }^{11}$ Research has shown that listservs for health care professionals are valuable resources that aid in the preparation of educational presentations, that alter policies or documentation, and that help shape practices or systems. $^{7,8}$

The professions of nursing, occupational therapy, and social work have capitalized on electronic communication by using listservs to share information and resources among colleagues at a frequency that fits their personal schedules. ${ }^{711}$ These professional listservs are often aimed at specific audiences and contexts, for example, "social work in palliative care" or "nursing in rehabilitation"; as such, listservs reduce isolation for some professionals in a specific practice area by facilitating contact and collaboration among professionals in different geographic locations. $^{7,8}$

Pharmacists adopting new roles in primary care in Canada are members of a listserv jointly hosted by the CSHP and the CPhA through their Primary Care Pharmacy Specialty Network (PC-PSN). The listserv was established in 2007 as a membership benefit of both organizations.
Regardless of the practice setting, demonstration projects have identified various types of knowledge and skills that support pharmacists' integration into primary care, including interviewing patients, documentation, collaboration, and knowledge of common therapeutic issues. ${ }^{14-18}$ Multiple challenges to team integration have also been identified in the literature. ${ }^{3}$ However, few studies have examined the experiences or learning needs of pharmacists who are actively attempting to evolve their primary care practices in the real world.

Informal learning has an important role for learning in practice. Opportunities for informal learning typically arise from an immediate need or curiosity. ${ }^{19}$ In contrast to most formal learning opportunities, for which specific topics are predetermined, immediate learning needs are often addressed through discussion with colleagues or through individual efforts to find information. Consultation with colleagues is particularly helpful when addressing complexities and issues at the time of decisionmaking. Examining listserv communication, where participants post questions related to immediate needs and reply to the questions of others, should help researchers and others to understand real-world experiences and the learning needs of pharmacists.

For this study, it was of interest to determine how pharmacists used the PC-PSN listserv in everyday practice. The objectives were to characterize membership and participation in the PC-PSN listserv and to examine the ways in which the listserv was used by analyzing day-to-day questions, concerns, and issues discussed. Ultimately, this knowledge will contribute to filling the notable gap in understanding real-world experience and the learning needs of pharmacists as their practices evolve.

\section{METHODS}

\section{Study Design}

This retrospective study involved quantitative and qualitative content analysis of textual data obtained from archived listserv communications. ${ }^{20}$ The project received ethics approval from Bruyère Continuing Care and the Ottawa Health Sciences Network. Representatives from both CPhA and CSHP granted approval, as did the chair of the PC-PSN. Individual consent from people who had posted to the listserv was not sought, because the perceived risk to listserv members was minimal. ${ }^{21}$ Nonetheless, the researchers were mindful of the ethical considerations of reporting findings and quoting participants. No identifying information was seen by anyone outside the research team. All staff and investigators were bound by confidentiality agreements and received only password-protected documents. In accordance with usual practice for document data analysis of Internet posts and archives, ${ }^{21}$ current PC-PSN members were informed of the project through the listserv, and permission was sought for use of long quotations. 


\section{Research Team}

The research team was composed of 5 academic pharmacists (B.F., T.J.S., L.D., N.K., N.W.), 1 academic family physician (G.R.), 1 pharmacy resident (M.T.), and 2 pharmacy co-op students working as research assistants (including L.S.). Several members of the team were members of the listserv (B.F., T.J.S., L.D., N.K., N.W.).

\section{Data Collection}

All archived posts, from inception of the listserv in 2007, were transferred from the listserv administrator to the research team. The sample used for the analysis reported here consisted of all posts from January 1 to December 31, 2010 (the most recent calendar year for which a complete set of data was available).

The archived messages for 2010 were uploaded, in chronological order, to the NVivo 8 software program (QSR International, Cambridge, Massachusetts). A second copy of the dataset, organized by individual participant, was uploaded to NVivo in a separate database to facilitate designation and reporting of demographic attributes, including number of posts attributed to individuals.

\section{Data Analysis}

A mixed-methods content analysis, including both quantitative and qualitative aspects, was used. ${ }^{22}$ The quantitative content analysis was used to categorize textual data from individual posters in a manner that facilitated identification of members' characteristics and their participation, as well as the types of content in the posts. The qualitative content analysis was then applied to the chronological database to identify themes regarding how the listserv was used. Both analyses contributed to the overall interpretation of the results. Figure 1 outlines the approach to data collection and analysis.

\section{Quantitative Content Analysis}

To help in data analysis, a series of codes were constructed to categorize data within the listserv texts. A 2-month portion of the 2008 archives was reviewed to generate these potential categories of data. The pharmacy resident (M.T.) and a research assistant (L.S.) created a coding manual with definitions and examples, which where refined after team discussion. The same body of posts (from 2008) was used for independent practice coding by the 2 coders and to determine whether further clarification was needed for definitions arising from this subset of data; minor changes were made, and the coding manual was finalized before testing with and coding of the 2010 data.

Using the coding manual, 2 team members (M.T. and L.S.) independently coded posts from 2010 for 5 moderate users and 5 heavy users. The Cohen kappa statistic was calculated to determine inter-rater reliability, as a means to ensure that the coding manual definitions were consistently interpreted and to lend trustworthiness to the analysis. ${ }^{23}$ The remaining 2010 data were coded by one team member (L.S.).

Demographic attributes (practice setting, academic affiliation, and geographic setting) were assigned to listserv participants in the NVivo software. Options for practice setting were family practice, community, hospital, ambulatory clinic, $\mathrm{CPhA}$, consultant, combination, other, and unknown. Geographic setting was defined as the province of practice, and participants were recorded as having an academic affiliation if such an

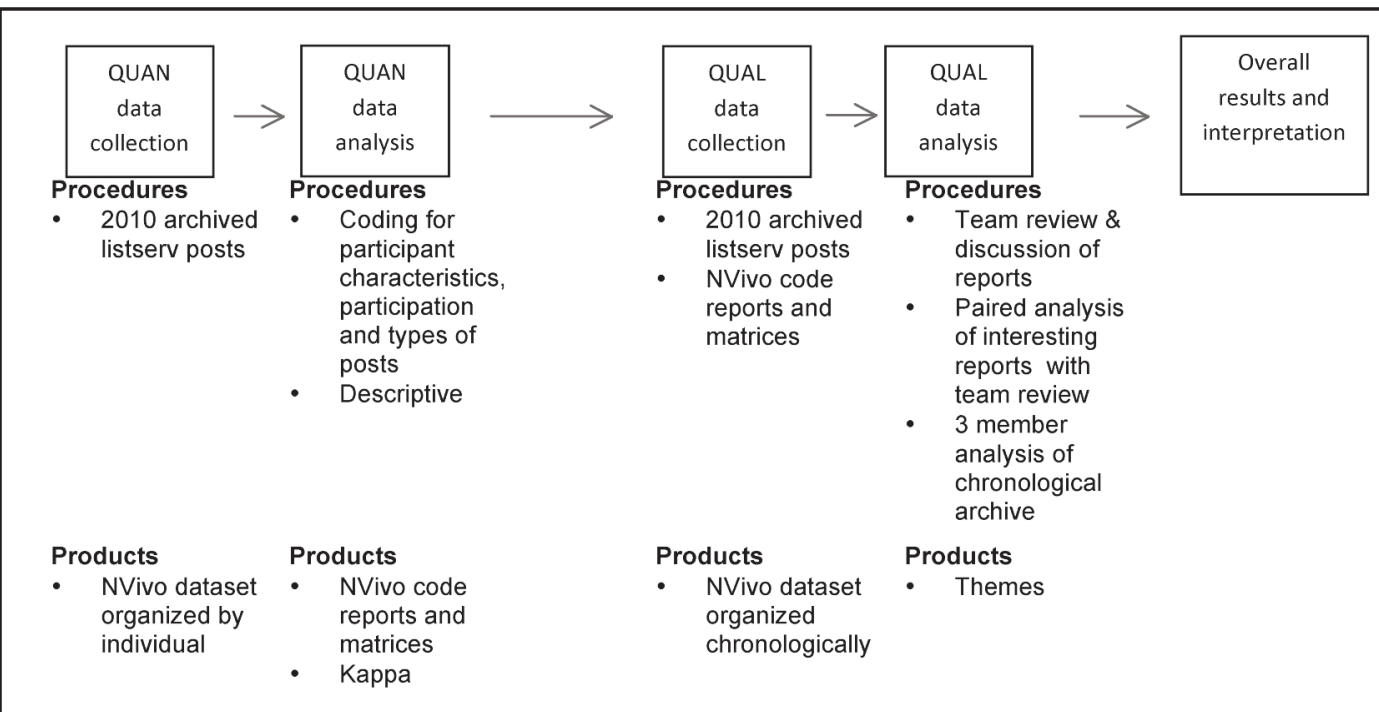

Figure 1. Diagram of quantitative (QUAN) and qualitative (QUAL) procedures used to explore content and use of listserv. 
affiliation was known. If these attributes could not be identified through examination of e-mail signatures or the content of a listserv post, the research team was asked to contribute their personal knowledge of the participants. A Google search was conducted for participants with unknown attributes.

Participation was categorized according to the number of posts over the 1-year period of analysis. Users were categorized as light (1-5 posts/year), moderate (6-13 posts/year), and heavy (14 or more posts/year), in accordance with other literature relating to listserv participation. ${ }^{9}$

Using the coding manual, each post was coded as representing at least 1 of 3 post types: a question, an answer or reply, or unsolicited information. Posts that contained both a question and an answer or reply were coded as falling in both categories. Other codes relating to content were then assigned to each post.

\section{Qualitative Content Analysis}

Three approaches to qualitative content analysis were used. First, descriptive reports for demographic attributes and for numbers and types of posts, as well as matrices comparing these data (generated from NVivo), were reviewed and discussed during an investigator team teleconference, which was recorded and transcribed. This approach offered an opportunity for team members to generate initial thoughts about the meaning and interpretation of data. The team identified areas for further analysis, and reports specific to these areas of interest (i.e., lists of related posts) were generated from NVivo. Each report was then read independently by pairs of team members, who discussed their findings at a second team teleconference. Each team member had the opportunity to describe his or her analysis, which the other reviewer could then corroborate or dispute. The teleconference was recorded and transcribed. In the last qualitative analysis approach, 3 team members (including B.F. and M.T.) independently read the 2010 archives in chronological order. This approach was added when it became apparent that the NVivo-generated reports and matrices captured individual

Table 1. Province of Practice of 2010 Listserv Participants

\begin{tabular}{lrc} 
Province & No. (\%) of Participants \\
& $(\boldsymbol{n}=\mathbf{1 2 9})$ \\
\hline British Columbia & 11 & $(8.5)$ \\
Alberta & 14 & $(10.9)$ \\
Saskatchewan & 14 & $(10.9)$ \\
Manitoba & 6 & $(4.7)$ \\
Ontario & 68 & $(52.7)$ \\
Quebec & 2 & $(1.6)$ \\
New Brunswick & 3 & $(2.3)$ \\
Nova Scotia & 8 & $(6.2)$ \\
Prince Edward Island & 0 & $(0)$ \\
Newfoundland and Labrador & 0 & $(0)$ \\
Unknown & 3 & $(2.3)$ \\
\hline
\end{tabular}

participation and related posts, but not the ebb and flow of conversation. For this part of the analysis, each of the 3 team members completed a data analysis template, which they then shared with the others during a half-day meeting, ultimately producing an agreed-upon document summarizing themes. This document was reviewed and discussed with the rest of the research team at a third teleconference, to generate key themes regarding how the listserv was used. The principal investigator (B.F.) and the pharmacy resident (M.T.) reviewed all meeting transcripts and the theme summary document to confirm these overall themes.

\section{RESULTS}

\section{Membership Characteristics and Participation}

Listserv membership grew throughout 2010, with 178 members reported in January and 244 members by December. Of the 244 year-end PC-PSN members, 129 (52.9\%) posted at least once during the year and were therefore considered "participants". The remainder of the dataset discussed here is limited to these participants.

More than half of the participants were practising in Ontario (Table 1). Participants practised in primary care in a variety of settings, the most frequent being family practice and community pharmacy (Table 2). Twenty-eight participants (21.7\%) had a known academic affiliation. For the remainder of participants, either there was no academic affiliation or this information could not be confirmed (i.e., academic affiliation unknown).

The kappa statistic (for coding of posts from 10 participants) was 0.78 , indicating acceptable agreement between coders for this sample of posts. ${ }^{22,24,25}$ Overall, 623 messages were posted to the listserv during 2010 . The activity level was highest in January (82 [13.2\%] of total posts), February (82 [13.2\%]), and March (92 [14.8\%]) and was lowest in July (29 [4.7\%]) and August (9 [1.4\%]) (Figure 2). Fifty-nine participants posted questions or requests. Almost half of these (27 [45.8\%]) had family practice as their primary site. In terms of types of posts, 201 posts were categorized as questions or requests, 422 as answers (responses that addressed specific questions), 102 as replies (responses that did not answer a question), and 56 as unsolicited information. The sum of these categories exceeds 623 because some posts were counted in multiple categories (e.g., a single post might answer a previous question and pose a new question). For every question or request, an average of 2.1 answers were posted.

Table 2, which classifies participants who posted questions or requests, answers, and replies in terms of their practice types, shows that participants from family health teams asked proportionally more questions than participants from other practice sites. 
This single copy is for your personal, non-commercial use only.

For permission to reprint multiple copies or to order presentation-ready copies for distribution, contact CJHP at cjhpedit@cshp.ca

Table 2. Participants' Activities on the Listserv of the Primary Care Pharmacy Specialty Network, by Practice Type*

Primary Practice Site; No. (\%) of Participantst

\begin{tabular}{|c|c|c|c|c|c|c|c|c|c|}
\hline Activity & Community & Hospital & Family & Clinic & Combination & CPhA & Consultant & Unknown & Other \\
\hline $\begin{array}{l}\text { No. }(\%) \text { of } \\
\text { participants } \\
(n=129)\end{array}$ & $28(21.7)$ & $16(12.4)$ & $40(31.0)$ & $15(11.6)$ & $3(2.3)$ & $9(7.0)$ & $5(3.9)$ & $6(4.7)$ & $7(5.4)$ \\
\hline $\begin{array}{l}\text { Posted question } \\
\text { or request } \\
(n=59)\end{array}$ & $13(22.0)$ & $8(13.6)$ & $27(45.8)$ & $7(11.9)$ & $1(1.7)$ & $0(0)$ & $1(1.7)$ & $2(3.4)$ & 0 \\
\hline $\begin{array}{l}\text { Answered } \\
\text { question or } \\
\text { request }(n=100)\end{array}$ & $21(21.0)$ & $14(14.0)$ & $28(28.0)$ & $14(14.0)$ & $3(3.0)$ & $6(6.0)$ & $5(5.0)$ & $4(4.0)$ & $5(5.0)$ \\
\hline $\begin{array}{l}\text { Posted reply } \\
\text { (not a specific } \\
\text { answer) }(n=40)\end{array}$ & $12(30.0)$ & $2(5.0)$ & $11(27.5)$ & $7(17.5)$ & $2(5.0)$ & $1(2.5)$ & $3(7.5)$ & $1(2.5)$ & $1(2.5)$ \\
\hline
\end{tabular}

CPhA = Canadian Pharmacists Association (i.e., staff member).

*For calendar year 2010.

tFor the first row, percentages are calculated in relation to the entire sample $(n=129)$. For second and subsequent rows, percentages are calculated in relation to total number of participants engaged in each type of activity (based on $n$ values reported in column 1).

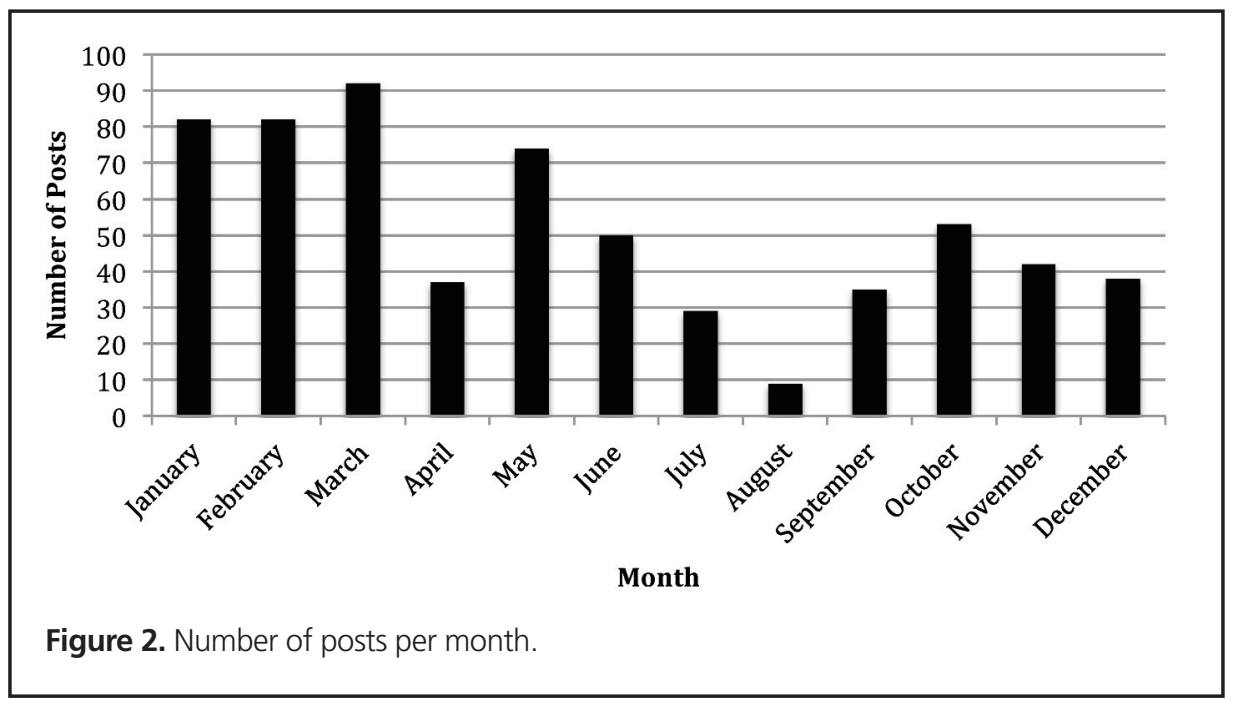

Thirty of the questions posed went unanswered by the end of the calendar year ("orphaned"). Overall, the topics for these unanswered posts did not differ from those for posts that received replies or generated conversation. It is possible that these posts were answered in private e-mail messages, but information about such correspondence was not available.

About half the listserv members (115/244 [47.1\%]) did not post during 2010, and slightly fewer (105 [43.0\%]) posted 5 times or less and were considered light users. Of the remaining 24 members, 15 (6.1\% of total) were classified as medium users (6-13 posts each), and $9(3.7 \%)$ were heavy users (> 14 posts each).

\section{How the Listserv Was Used}

Three themes emerged with regard to how people used the listserv: to discuss information on a diverse set of topics, to seek solutions for complex problems, and as a setting for mentorship.

\section{Discussion of Diverse Topics}

Categories of topics discussed were grouped in terms of therapeutic areas (see Figure 3) and practice management issues (see Figure 4). Topics included patient-specific therapeutic questions, questions about indications for and availability of medications, practice management needs, and simple exchange of information among participants (Table 3). Participants frequently sought support from and shared resources with their peers to aid in starting or developing their respective practices or in caring for patients. Individual posts and threads varied in length and detail, with patient-related questions ranging from basic and simple to complex and difficult. Responses, in turn, ranged from short factual replies to lengthy replies, as well as replies generating conversation and polite debate among participants. 


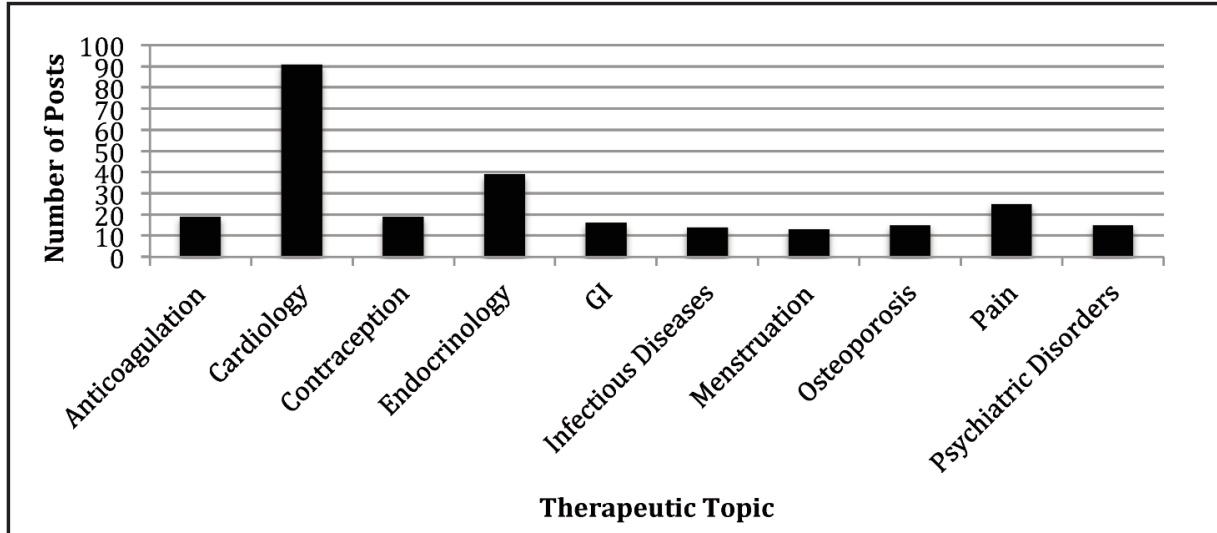

Figure 3. Top 10 therapeutic topics. $\mathrm{Gl}$ = gastrointestinal.

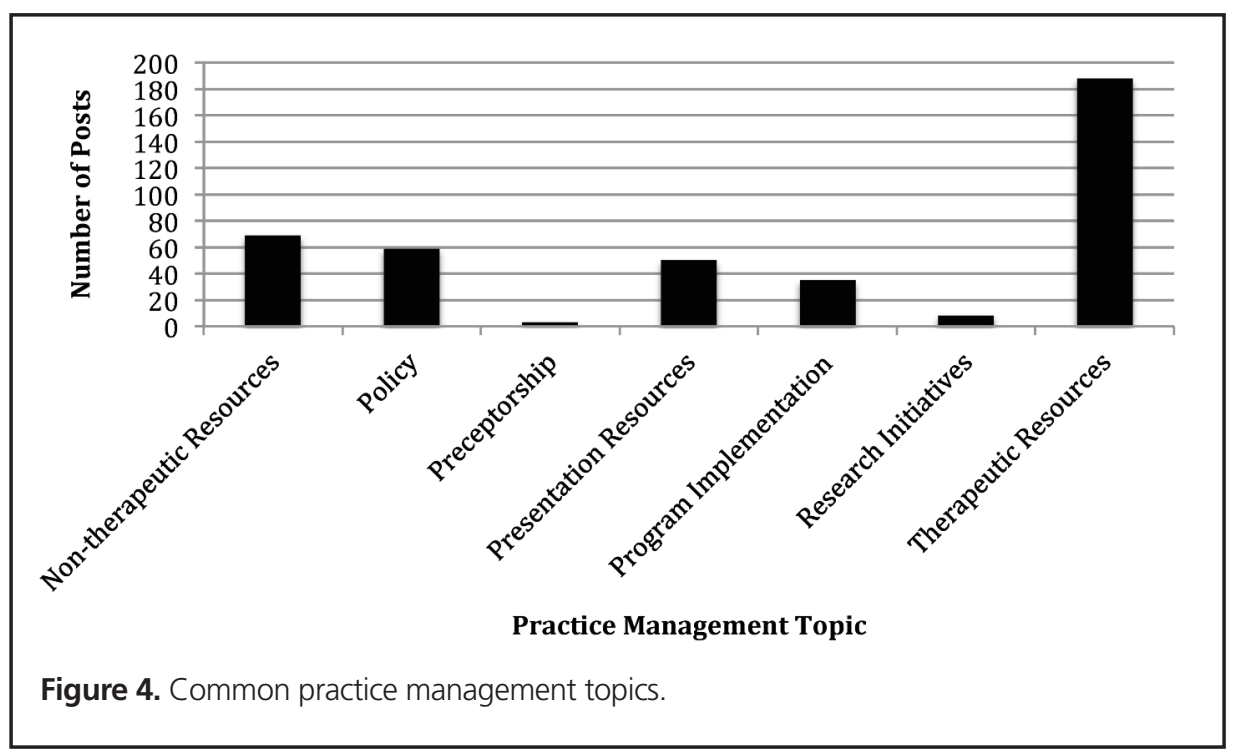

\section{Solutions for Complex Problems}

Participants used the listserv to seek information related to the care of patients with complex medical conditions and needs. The level of complexity varied and was associated with multiple health-related factors, including disease states, housing, income, literacy, level of caregiver support, and level of cognition. In these discussions, participants responding to original requests often sought additional information about the patient, the situation, or the main question. For example, clinical or laboratory information was often requested.

There were examples of disagreement among participants with respect to answers or advice provided for patient management. At times, participants struggled to apply evidence to specific patients. For example, one participant commented that "We have difficulty assessing probability of benefits and harms. ..." Participants also had difficulty integrating patients' perspectives, their lifestyles, the costs of therapy, and nonpharma- cological options with evidence. For example, in reply to one participant's question, "Why Lantus [insulin glargine] BID [twice daily] when it can be given HS [at bedtime] and have the patient on regular insulin instead?" the response was, "He cannot read, and has poor vision. ... It is pretty important to put reality into context-this is a man who grew up very poor with low education, always shy, always does his own thing."

Participants sometimes used the listserv as the first step in seeking information before consulting other resources. This type of question or request prompted one participant to subsequently post a question that included the following comment: "I will endeavour to not be so lazy in the future and exert more discretion in my use of the listserv!"

\section{Forum for Mentorship within a Community}

Among the participant roles that emerged from the data (learner, leader, mentor, and expert), mentorship appeared 


\section{Table 3. Examples of Topic Diversity}

Topic

Patient-specific

therapeutic questions

Quoted Example

I was wondering if anyone could offer some advice on the use of nortriptyline in a patient with AFib? We have a morbidly obese [patient] with multiple issues. He has AFib and is describing pain in his feet that may be related to diabetic neuropathy. He also has some issues with difficulty sleeping. We are thinking of trying [nortriptyline] $10 \mathrm{mg}$ ghs (titrate to $50 \mathrm{mg}$ qhs) to help with the neuropathy (among other strategies for contributing factors) with the potential for a beneficial influence on his sleep. However, he also has AFib. I'm not sure how concerned to be about the potential cardiac toxicity that could be associated with TCAs. Does anyone have experience using [nortriptyline] in someone with AFib? Any particular monitoring you would recommend?

\begin{tabular}{ll}
\hline Medication indication & Has anyone come across the use of low dose Naltrexone for Crohn's disease? \\
\hline Medication availability & $\begin{array}{l}\text { Anyone know anything about a shortage of allopurinol? We are getting faxes from local } \\
\text { community pharmacies that they cannot get any. Is this a national issue? What is the } \\
\text { problem? }\end{array}$ \\
\hline Practice management needs & $\begin{array}{l}\text { I am looking to see if there are any templates out there that you have found useful in } \\
\text { conducting a medication review. }\end{array}$ \\
\hline Provision of information (unsolicited) & $\begin{array}{l}\text { For those interested, here is the recent "early" release of the Clinical Practice Guidelines for } \\
\text { Osteoporosis. Officially just launched at the ASBMR meeting in Toronto this week. }\end{array}$ \\
\hline
\end{tabular}

$\mathrm{AFib}=$ atrial fibrillation, $\mathrm{ASBMR}=$ American Society for Bone and Mineral Research, TCA = tricyclic antidepressant.

relevant for many. Learners were typically looking for assistance or reassurance regarding a clinical or management issue, for example, "It's one of those cases where I have made up my mind in terms of what I want to do but there is a small part of me second-guessing my plan. ..." Mentors provided support to learners, asked probing questions to generate discussion, and demonstrated effective question-posing techniques. It was apparent that many participants were unclear about appropriate structure and content for questions and requests posted to the listserv, and the mentors attempted to assist and guide participants as they learned this new skill: "For patient care information, please include only relevant de-identified patient information/ data ... As much as possible, try to submit a focused clinical question that you can apply back to your relevant patient. This will save time on the part of the reader and minimize any conflict from a confidentiality perspective." Experts were participants with apparent therapeutic expertise who often provided lengthy, detailed answers to questions, including references or critically appraised literature. The role of leader was often assumed by the PC-PSN listserv administrator, whose posts frequently included information about listserv rules and regulations.

The concept of community was very present on the listserv, and several members made reference to the positive benefits of participating, including " $[\mathrm{I}] \mathrm{t}$ has been so inspiring to witness the support (and especially the humour) you provide each other-it is great to be a part of this resource!"

\section{DISCUSSION}

The PC-PSN listserv is a virtual environment where pharmacists can share information and seek solutions to address complex problems, as well as being a forum for mentorship and community.
The level of participation varied widely among listserv members, with about half posting at least once in 2010. Although $9.8 \%$ of members posted 6 times or more during 2010, about half (47.1\%) did not post at all. Lack of posting may have related partly to members' lack of familiarity with one another. Research on Internet communication frequently refers to people who observe but do not post as "lurkers" or "noncontributors" . ${ }^{26-28}$ Members who do not contribute to the discussion may benefit by reading, and other health care practitioners have found that this activity helps them to stay current in their field. ${ }^{8,29}$ Murty and others ${ }^{7}$ suggested that new members remain observers on a listserv for a period of time, until they feel comfortable posting. The authors of one study who explored online listening behaviours equated noncontributors with listeners in face-to-face conversations; they concluded that listening is a distinct and important part of participation in online discussions. ${ }^{27}$ However, although noncontributors may themselves benefit by reading, they do not necessarily contribute to the learning of others. Exploring and understanding noncontributors' perceived value of observing the listserv, as well as their reasons for not posting, represents a new area for research that might help to define how participants can get the most out of listserv membership.

Pharmacists practising primarily in family practice asked proportionally more questions than those from other areas of pharmacy practice. This difference may be because pharmacists in family practice work with various other health care professionals but seldom have a pharmacist colleague on site with whom to consult. They may receive referrals for complex patients from the family physicians with whom they work and may use the listserv to pose clinical questions or solicit opinions from pharmacist colleagues if a greater level of decision-making regarding patient care is required than that to which they have been accustomed. 
The diversity in questions and topics discussed on the listserv illustrates the complexity and variety of issues that pharmacists encounter on a daily basis. In a study of an occupational therapy listserv, Long and others ${ }^{9}$ concluded that the topics generating the most discussion paralleled current practice trends and issues pertinent to day-to-day practice. The PC-PSN had a wide variety of topics, many of which reflected current practice challenges (such as drug availability) and contemporary pharmacy practice issues (such as integration of pharmacists into family practice and the resources required to do so).

In some cases, posters used the listserv as the first step in seeking information. This finding is consistent with research that has explored information-seeking by health care professionals, whereby trusted colleagues are often the first source of information, along with personal libraries, Internet sources, and the medical literature. ${ }^{30}$ In contrast, instructions for the PC-PSN listserv indicate that participants should do a literature search before posting and should use the listserv only after they have completed their own search. ${ }^{31}$ A study analyzing the information-seeking behaviour of hospital pharmacists in Greece noted that lack of time and poor organization were the greatest obstacles to finding information..$^{32}$ Utilization of the listserv may be seen as a time-saving practice and a way to draw on the expertise of more skilled or experienced pharmacists. However, given the potential negative response (from other participants) if posting to the listserv is perceived as "laziness", individual members may want to be cautious about using the listserv too frequently in this way.

In their description of online communities of practice, Lai and others ${ }^{33}$ identified 4 categories of participant roles that are necessary for online groups to succeed: leaders, core members, support persons, and community members. Within the leader category is the moderator or facilitator, which is similar to the role of the PC-PSN listserv administrator. Core members include "subject matter experts", and support persons include mentors and those providing technical support. Finally, the community members are the learners within the online community. ${ }^{33}$ Pharmacists acting as mentors in the PC-PSN listserv online community supported other members and asked probing questions to clarify information requests on the listserv. Members of the PC-PSN online community of practice have adopted the roles described by Lai and others, ${ }^{33}$ which appear to be necessary for successful online groups. We hypothesize that these assumed roles may reflect the level of experience of participants, and this represents an area for future research.

A relatively high proportion (more than one-fifth) of participants in the PC-PSN listserv had an academic affiliation. This large academic presence may explain the amount of mentoring that was apparent, as well as the expert roles that emerged. It might also have led to information-sharing and support, as well as facilitating discussion.
Participants frequently sought advice and support from other members of the listserv. An analysis of a listserv used by social workers in the palliative care setting suggested that collaboration through the listserv might increase competence and the potential for social workers to contribute to that area of practice. ${ }^{7}$ The information-sharing observed in this pharmacy listserv may also have the potential to increase members' competence, as well as their contribution to patient care in various types of pharmacy practice.

At times, participants were quick to point out the existence of evidence-based recommendations, but they did not always take patient-related factors into account, perhaps because initial posts often did not include relevant patient-specific information. Alternatively, this situation may indicate a learning need for pharmacists, in terms of understanding how to extrapolate evidence to individual patients. Faculties of pharmacy continue to expand the evidence-based medicine and critical appraisal aspects of their curricula in the hope that new pharmacists will gain the skills and confidence required to extrapolate evidence to individual patients. Understanding whether and how such curricular changes have accomplished this goal is an important area for further research.

This study had some limitations. About half of the PC-PSN members did not post, so it was not possible to assess their demographic characteristics or draw conclusions about their participation. The total number of members (and hence the number of noncontributors) may have been overestimated, as it was not possible to track when members left the listserv. In addition, direct communication between members could not be captured, and individual members were not interviewed or asked to confirm themes identified in the analysis.

Efforts were made to ensure the trustworthiness of the interpretation of the content and uses of the listserv through an iterative process involving both quantitative and qualitative content analyses, with steps to maximize the reliability of data interpretation..$^{22}$ This recursive approach went beyond a surfacelevel categorization of content to ensure that the results made sense from a number of perspectives and through a number of lenses, resonating accurately with analysts. Several members of the investigator team were also members of the listserv and (with acknowledgement of their potential bias from the outset) were able to provide input about how the results of this study resonated with their listserv experience. The kappa value for inter-rater reliability of 0.78 is considered an acceptable level of agreement in qualitative research. ${ }^{22}$ Interpretation of data often depends on context, and some data are open to different interpretations, which are in part dependent on the researcher's perspective. ${ }^{22}$

\section{CONCLUSIONS}

Content analysis of posts to the PC-PSN listserv in 2010 suggested that this listserv is a medium for information-sharing 
and a forum for mentorship. The results presented here may aid PSN leaders and their parent organizations in understanding how listservs are used by pharmacists, as well as their value and challenges. The topics of posts varied widely, and therefore it was not possible to identify specific therapeutic topics suitable for traditional large-group or written continuing education content. However, common needs appeared to be learning how to pose therapeutic questions effectively for discussion and extrapolating evidence to individual patients. Educators should be alert to these needs and should consider incorporating approaches to addressing them at both undergraduate and continuing education levels, to enable pharmacists to more effectively discuss patient care issues and extrapolate evidence to individual patients. The high use of and appreciation for an online forum such as the PC-PSN listserv for seeking information and obtaining mentoring support was clear, and the profession should pay attention to the benefits of this approach for advancing learning and patient care.

This research adds to the growing body of evidence that listservs used by health care professionals represent online communities with distinct participant roles, including the learner, the mentor, and the expert. Pharmacy listserv hosts should consider the importance of facilitating these roles to maximize participation in and usefulness of listservs.

Future research building on this study could involve interviewing participants, as well as members who did not post (i.e., noncontributors) to determine their respective perceptions of the usefulness of the listserv and to identify methods to maximize participation and learning. In addition, analysis of discussions of complex patient care could be used to gain understanding of how knowledge is constructed through online exchanges.

\section{References}

1. Anderson S. The state of the world's pharmacy: a portrait of the pharmacy profession. J Interprof Care. 2002;16(4):391-404.

2. Battu K, Emberley P, Lee V, Seguin J, Zhang M, Huang Y, et al. Pharmacists' medication management services: environmental scan of Canadian and international services. Ottawa (ON): Canadian Pharmacists Association; 2010 [updated 2011, 2012, 2013; cited 2013 Aug 17]. Available from: http://blueprintforpharmacy.ca/docs/kt-tools/canada-environmental-scanof-pharmacy-services---cpha-october-2013---final.pdf

3. Jorgenson D, Dalton D, Farrell B, Tsuyuki RT, Dolovich L. Guidelines for pharmacists integrating into primary care teams. Can Pharm J. 2013; 146(6):342-52.

4. Grindrod K, Forgione A, Tsuyuki RT, Gavura S, Giustini D. Pharmacy 2.0: a scoping review of social media use in pharmacy. Res Soc Adm Pharm. 2014;10(1):256-70.

5. Networking [web page]. Bethesda (MD): American Society of HealthSystem Pharmacists; [cited 2013 Aug 17]. Available from: www.ashp.org/ menu/MemberCenter/SectionsForums/SOPIT/Networking.aspx

6. Pharmacy Specialty Networks (PSNs) [web page]. Ottawa (ON): Canadian Society of Hospital Pharmacists; 2013 [cited 2013 Aug 17]. Available from: www.cshp.ca/cshpNetwork/psn/index_e.asp

7. Murty SA, Gilmore K, Richards KA, Altilio T. Using a LISTSERV ${ }^{\mathrm{TM}}$ to develop a community of practice in end-of-life, hospice, and palliative care social work. J Soc Work End Life Palliat Care. 2012;8(1):77-101.

8. Thompson TL, Penprase B. RehabNurse-L: an analysis of the rehabilitation nursing LISTSERV experience. Rehabil Nurs. 2004;29(2):56-61.
9. Long S, de Jonge D, Ziviani J, Jones A. Paediatricots: utilisation of an Australian list serve to support occupational therapists working with children. Aust Occup Ther J. 2009;56(1):63-71.

10. Hew KF, Hara N. An online listserv for nurse practitioners: a viable venue for continuous nursing professional development? Nurse Educ Today. 2008;28(4):450-7.

11. McCartney PR. Internet communication and discussion lists for perinatal nurses. J Perinat Neonatal Nurs. 1999;12(4):26-40.

12. Lucas MR. A private caregiver ListServ: maximum benefit for minimum cost. J Psychosoc Oncol. 2011;29(2):168-74.

13. Kaplan K, Salzer MS, Solomon P, Brusilovskiy E, Cousounis P. Internet peer support for individuals with psychiatric disabilities: a randomized controlled trial. Soc Sci Med. 2011;72(1):54-62.

14. Austin Z, Dolovich L, Lau E, Tabak D, Sellors C, Marini A, et al. Teaching and assessing primary care skills: the family practice simulator model. Am J Pharm Educ. 2005;69(4):500-7 (article 68).

15. Budzinski JW, Farrell B, Pluye P, Grad RM, Repchinksy C, Jovaisas B, et al. An online knowledge resource and questionnaires as a continuing pharmacy education tool to document reflective learning. Am J Pharm Educ. 2012; 76(5):Article 82.

16. Farrell B, Pottie K, Haydt S, Kennie N, Sellors C, Dolovich L. Integrating into family practice: the experiences of pharmacists in Ontario, Canada. Int J Pharm Pract. 2008;16(5):309-15.

17. Howard M, Trim K, Woodward C, Dolovich L, Sellors C, Kaczorowski J, et al. Collaboration between community pharmacists and family physicians: lessons learned from the Seniors Medication Assessment Research Trial. $J$ Am Pharm Assoc. 2003;43(5):566-72.

18. Lee A, Cameron A, Farrell B, Beales J. Experiential rotations at family health teams - perspectives of students, preceptors, and other team members [presentation]. Association of Faculties of Pharmacy of Canada conference; June 2009; Halifax (NS).

19. Granger CA, Morbey ML, Lotherington H, Owston RD, Wideman $\mathrm{HH}$. Factors contributing to teachers' successful implementation of IT. J Comput Assisted Learn. 2002;18(4):480-8.

20. Krippendorf K. Content analysis:an introduction to its methodology. $2 \mathrm{nd}$ ed. Thousand Oaks (CA): Sage Publications; 2004.

21. Sixsmith J, Murray CR. Ethical issues in the documentary analysis of Internet posts and archives. Qual Health Res. 2001;11(3):423-32.

22. Julien H. Content analysis. In: Given LM, editor. The SAGE encyclopedia of qualitative research methods. Thousand Oaks (CA): Sage Publications; 2008. p. 120-1.

23. Viera AJ, Garrett JM. Understanding interobserver agreement: the kappa statistic. Fam Med. 2005;37(5):360-3.

24. NVivo 8 Help: using the software. Doncaster (Australia): QSR International Pty Ltd; 2008 [cited 2013 Aug 17]. Available from: http://download. qsrinternational.com/Document/NVivo8/NVivo8-Help-Using-theSoftware.pdf

25. Fleiss JL. Statistical methods for rates and proportions. 2nd ed. New York (NY): JohnWiley; 1981.

26. Nonnecke B, Preece J. Lurker demographics: counting the silent. CHI Lett. 2000;2(1):73-80.

27. Wise AF, Speer J, Marbouti F, Hsiao YT. Broadening the notion of participation in online discussions: examining patterns in learners' online listening behaviors. Instr Sci. 2013;41:323-43.

28. Collison G, Elbaum B, Haavind S, Tinker R. Facilitating online learning: effective strategies for moderators. Madison (WI): Atwood Publishing; 2000.

29. Schloman BF. The internet as community: communication avenues for health professionals and health consumers. Online J Issues Nurs. 2002;7(1):8.

30. Leckie GJ, Pettigrew KE, Sylvain C. Modeling the information seeking of professionals: a general model derived from research on engineers, health care professionals, and lawyers. Library Q. 1996;66(2):161-93.

31. Is there any email etiquette that I should be aware of? In: Pharmacy Specialty Networks, Frequently asked questions. Ottawa (ON): Canadian Society of Hospital Pharmacists; 2013 [cited 2013 Dec 9]. Available from: www.cshp.ca/cshpNetwork/psn/psn-faq_e.asp\#etiquette

32. Kostagiolas PA, Aggelopoulou VA, Niakas D. A study of the information seeking behaviour of hospital pharmacists: empirical evidence from Greece. Health Info Libr J. 2011;28(4):302-12. 
This single copy is for your personal, non-commercial use only.

For permission to reprint multiple copies or to order presentation-ready copies for distribution, contact CJHP at cjhpedit@cshp.ca

33. Lai KW, Pratt K, Anderson M, Stigter J. Literature review and synthesis: online communities of practice. Wellington (New Zealand): New Zealand Ministry of Education; 2006.

Melanie Trinacty, BSc, BScPharm, is a Clinical Pharmacist, The Ottawa Hospital, Ottawa, Ontario.

Barbara Farrell, BScPhm, PharmD, FCSHP, is the Clinical and Research Coordinator in the Pharmacy Department, Bruyère Continuing Care, Ottawa, Ontario; a Scientist in the Bruyère Research Institute and C T Lamont Centre, Ottawa, Ontario; an Assistant Professor in the Department of Family Medicine, University of Ottawa, Ottawa, Ontario; and an Adjunct Assistant Professor in the School of Pharmacy, University of Waterloo, Waterloo, Ontario.

Theresa J Schindel, BSP, MCE, FCSHP, is Clinical Associate Professor in the Faculty of Pharmacy and Pharmaceutical Sciences, University of Alberta, Edmonton, Alberta.

Lisa Sunstrum, BSc, was (at the time of the study) a student in the School of Pharmacy, University of Waterloo, Waterloo, Ontario. She is now a Pharmacy Resident with the Toronto Western Family Health Team, University Health Network, Toronto, Ontario.

Lisa Dolovich, BScPhm, PharmD, MSc, is Research Director and Professor in the Department of Family Medicine, and is Scientist and Associate Director, Centre for Evaluation of Medicines, McMaster University, Hamilton, Ontario.
Natalie Kennie, BScPhm, PharmD, was (at the time of the study) a Clinical Pharmacist, Summerville Family Health, and Team Assistant Professor (status only), Department of Family and Community Medicine, Faculty of Medicine, and the Leslie Dan Faculty of Pharmacy, University of Toronto, Toronto, Ontario. She is now the Second Year Skills Lab Coordinator, College of Pharmacy, Dalhousie University, Halifax, Nova Scotia.

Grant Russell, MBBS, FRACGP, PhD, is Head of School and Professor of General Practice Research in the School of Primary Health Care and Director of the Southern Academic Primary Care Research Unit, Monash University, Melbourne, Australia.

Nancy Waite, BScPhm, PharmD, FCCP, is Associate Director, PracticeBased Education, Ontario College of Pharmacists, Toronto, Ontario; and Professor in Pharmacy Innovation and Associate Professor, School of Pharmacy, University of Waterloo, Waterloo, Ontario

Competing interests: None declared.

Address correspondence to:

Dr Barbara Farrell

Bruyère Research Institute

43 Bruyere Street

Ottawa ON K1N 5C8

e-mail: bfarrell@bruyere.org

\section{Acknowledgements}

The research team gratefully acknowledges the contribution of University of Waterloo co-op pharmacy student Karishma Kak to the data analysis.

Funding for this study was provided by the Canadian Society of Hospital Pharmacists Research and Education Foundation. 